\title{
Sperm DNA Fragmentation in Rams Vaccinated with Miloxan
}

\author{
J. Gosálvez ${ }^{*}, 1$, J. M. Vázquez², M. Enciso ${ }^{1}$, J.L. Fernández ${ }^{3}$, A. Gosálbez ${ }^{1}$, J. R. Bridle ${ }^{4}$ and \\ C. López-Fernández ${ }^{1}$ \\ ${ }^{I}$ Departamento de Biología, Unidad de Genética, C/Darwin $n^{\circ}$ 2, Universidad Autónoma de Madrid, Madrid 28049, \\ Spain \\ ${ }^{2}$ Ovigen, Granja Florencia, Zamora 49800, Spain \\ ${ }^{3}$ Sección de Genética y Unidad de Investigación, Complejo Hospitalario Juan Canalejo, As Xubias, Coruña, Spain \\ ${ }^{4}$ School of Biological Sciences, University of Bristol, BS8 1UD, UK
}

\begin{abstract}
Sperm DNA fragmentation was analysed in 113 semen samples obtained from different rams over a period of one year. Semen samples were collected from: unvaccinated rams between January and June (Control group 1; CG1); vaccinated rams at least 70 days after vaccination between October and December (Control group 2; CG2); vaccinated rams 20 days after vaccination (Vaccinated group 1; VG1); and vaccinated rams 40 days after vaccination (Vaccinated group 2; VG2). Results show Miloxan, the vaccine of interest in this study, increased the percentage of sperm cells with fragmented DNA by 10-fold on average (from $6.5 \pm 7.9$ to $63.4 \pm 24.2$ ). However, the negative impact of vaccination on sperm DNA fragmentation appeared to reversible; near normal levels of sperm DNA fragmentation had been restored 40 days after vaccination $(21.7 \pm 10.6)$. On the basis of these data, the use of semen samples from vaccinated animals should be avoided until at least one month after vaccination.
\end{abstract}

\section{INTRODUCTION}

Sperm DNA Fragmentation (SDF) has been the subject of numerous studies because loss of fertility has been shown to be highly correlated with a high frequency of nuclei containing damaged DNA in human [1] and in other mammals $[2,3]$. However, based on human studies, the relationship between a high frequency of sperm containing fragmented DNA and the capacity of the male to generate fertilization is controversial [4]. The origin of DNA fragmentation is mostly unknown, although apoptosis, oxidative stress, or persistence of DNA breaks produced during the chromatin protamination process in spermiogenesis, could be direct causes. It is also known that some external effectors such as exposure to environmental pollutants, smoking, or genetic characteristics such as a massive reduction of telomeric DNA sequences, may trigger sperm DNA fragmentation [5, 6]. The assessment of SDF in organisms used for reproductive purposes is therefore of interest, especially when the individuals concerned have encountered a stress episode. This is because the assessment of classical parameters of sperm quality does not fully correlate with the sperm DNA quality $[7,8]$. In particular, SDF should be periodically assessed along the reproductive life of those animals used repeatedly to retrieve semen samples for assisted reproduction, in order to avoid using damaged sperm for fertilization.

Infectious agents may interfere with genetic programs controlling the organism's normal development with a clear detrimental effect on individual fitness. In terms of reproduction, it is known that infectious agents can affect embryonic

*Address correspondence to this author at the Departamento de Biología, Unidad de Genética, C/Darwin $\mathrm{n}^{\circ}$ 2, Universidad Autónoma de Madrid, Madrid 28049, Spain; E-mail: jaime.gosalvez@uam.es survival, ovulation rates and fertilization $[9,10]$. From a similar viewpoint, immunological infertility in males has been associated with presence of auto- or iso-antibodies and their effect on sperm proteins. These antibodies can prevent the accessibility of spermatozoal proteins at various stages during the fertilization process and therefore induce infertility. A number of sperm-specific proteins are therefore being considered as candidates for the development of vaccines for reducing fertility $[11,12]$.

Although vaccines are composed of weakened, dead germs or toxins, when injected to living animals they may produce side-effects, generally through the activation of the immune system. Vaccination may affect the various standard seminal parameters such as sperm motility, concentration and production rate of abnormal forms [13]. The aim of the present investigation was to analyse if subcutaneous vaccination of rams with Miloxan (Clostridium perfringens type C, $\mathrm{D}$ and $C$. oedematiens type B) had any effect on the percentage of sperm cells with fragmented DNA.

\section{MATERIAL AND METHODS}

\section{Semen Samples, Collection and Preparation}

One hundred and thirteen semen samples of different individuals from four main different races of ram (Castellana, Assaf, Lacaune and Churra) collected along one year were included in the analysis. All animals belong to the same Genetic Centre (Ovigen, Zamora, Spain). The animals were vaccinated with Miloxan (Clostridium perfringens type C, D and Clostridium oedematiens type B; Merial, Lyon, France). Two $\mathrm{ml}$ were subcutaneously administered to each animal. Sperm samples included in the analysis were collected at different periods throughout the year and classified into four groups: Control Group 1 (CG1): sperm samples obtained from January to June from unvaccinated animals. Vaccina- 
tion Group 1 (VG1): sperm samples obtained in July 20 days post-vaccination. Vaccination Group 2 (VG2): sperm samples obtained in August 40 days post-vaccination. Control Group 2 (CG2): sperm samples obtained in October to December at least 70 days post-vaccination. Unfortunately, during the experiment, it was only possible to assign semen samples to particular animals in $35 \%$ of cases. Samples within each pre-established groups were therefore considered to be independent clusters of individuals.

All semen samples were collected with the use of an artificial vagina. Immediately after collection, the semen was diluted to a final concentration of $43 \times 10^{8}$ spermatozoa $/ \mathrm{ml}$ with a commercial egg yolk-based extender (Triladylt; Minitube Canada, Woodstock, Canada) and frozen using $0.2 \mathrm{ml}$ straws. Only sperm samples considered of sufficiently high quality for standard parameters, including volume, concentration, motility, acrosomes and positive endosmosis, are currently frozen at the Ovigen Center. All animals were aged 2 to 4 years, healthy, and controlled for feeding, housing, and photoperiod conditions. These stocks are currently being maintained for breeding purposes.

\section{Sperm DNA Fragmentation Analysis}

To determine the percentage of sperm cells with fragmented DNA, i.e. DNA Fragmentation Index (SDFi), the Sperm-Halomax ${ }^{\circledR}$ kit (Halotech-DNA SL, Madrid, Spain) was used. This methodology is a variant on the SCD (Sperm Chromatin Dispersion) test and has been used to assess sperm DNA fragmentation in mouse [6], pig [14, 15] and bull [16]. For each experiment, frozen straws were thawed and different aliquots were prepared to a final concentration of $10-15 \times 10^{6}$ spermatozoa $/ \mathrm{ml}$. Twenty five microliters of semen diluted to $10-15 \times 10^{6}$ spermatozoa per millilitre were added to a vial containing low melting point agarose and mixed. Pre-treated slides were placed onto a metallic plate cooled to $4^{\circ} \mathrm{C}$. A drop of the agarose-sperm mix was then spread onto the treated face of the slide and covered with a glass coverslip for 5 minutes at $4^{\circ} \mathrm{C}$. The coverslip was smoothly removed, and the slide was horizontally placed in $10 \mathrm{ml}$ of the lysing solution provided in the kit, to remove membranes and proteins. Finally, slides were washed for 5 min, dehydrated in sequential 70,90 and $100 \%$ ethanol baths. The sperm were then stained for fluorescence microscopy with DAPI in Vectashield Mounting Medium H-1000 (Vector, USA) followed by 2, 7 - dibrom - 4 - hydroxyl mercuryfluorescein di-sodium salt (DMF; Sigma, USA). The dual emission fluorochrome combination used in the present experiment, allowed simultaneous visualization of DNA (blue) and proteins (green) respectively using a dual band pass fluorescence filter block or, alternatively, a single emission could also be observed using a single band pass fluorescence filter block.

Fluorescence microscopy was used for automatic sperm counting using the Sperm Class Analyzer DNA module (Microptic SL, Barcelona, Spain). The SCA software discriminated between spermatozoa that showed a small halo of spreading of chromatin loops (sperm containing unfragmented DNA) and large or medium halo of diffused chromatin fragments (sperm containing fragmented DNA). This software was coupled to a Leica DMLA (Leica SA, Germany) motorized fluorescence microscope, controlled with
Leica based software, for automatic scanning and image digitalization of each slide. Magnification lenses 20x were used for facility of cell counting. A minimum of 800 spermatozoa per sample were counted. The SDFi (percentage of sperm cells with fragmented DNA) was then calculated. Statistical analysis was performed using Minitab version 14 for Windows.

\section{RESULTS AND DISCUSSION}

Sperm samples processed for DNA fragmentation visualization showed basically two different spermatozoa morphologies. Those nuclei that remained compact or displayed very small halos of chromatin spreading corresponded to spermatozoa harbouring unfragmented DNA (Fig. 1a,c). By contrast, those sperm nuclei which exhibited medium or large peripheral halos of diffusion of chromatin spots (Fig. $\mathbf{1 b}, \mathbf{d})$, contained fragmented DNA [16].

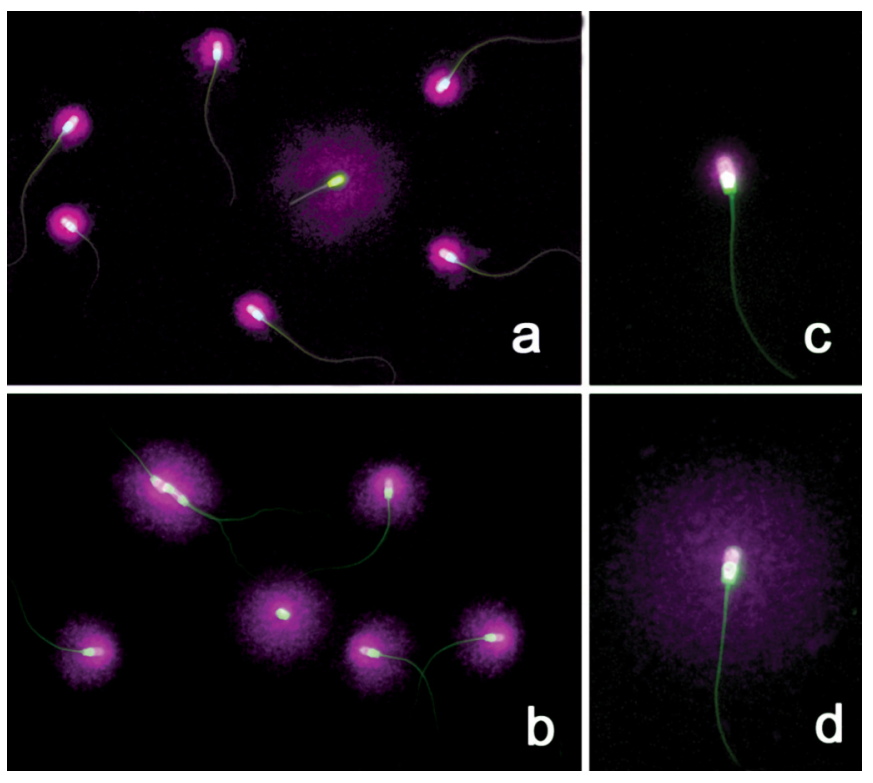

Fig. (1). Visualization of the sperm DNA fragmentation in ram under fluorescence-microscopy. (a) Sperm sample showing a low SDFi. (b) Sperm sample of an individual after 20 days of vaccination where most of the sperm cells exhibit a large dispersion of the chromatin. (c) Selected nuclei from a sperm cell containing unfragmented DNA. (d) Selected nuclei from a sperm cell containing fragmented DNA. In all cases, blues colour corresponds to DNA, whereas protein fluoresces in green and is mainly labelling the flagelum and sperm core after the SCD test.

The observed range of SDFi in the CG1 (January to June), was from individuals presenting nearly $0 \%$ of sperm DNA fragmentation, to others exhibiting about $41 \% \%$ of SDFi, The mean value of SDFi or this period was 6.4+7.9. The animals studied between October and December (CG2) showed a similar distribution of SDFi values $(5.7+4.5)$ and significant differences between both periods of analysis were not obtained based on arc-sine transformed data (one-way ANOVA: $F=0.16 ; p=0.7$ for 1 and $68 \mathrm{df}$ ). The condition of SDF 20 and 40 days post vaccination was very different (Fig. 2). SDFi post vaccination (VG1) significantly increased with a mean value of $63.4+24.2$ (one-way ANOVA, compared to CG1 and CG2 combined: $F=484.9$; $\mathrm{p}<0.0001$ for 1 and $101 \mathrm{df}$ ). 


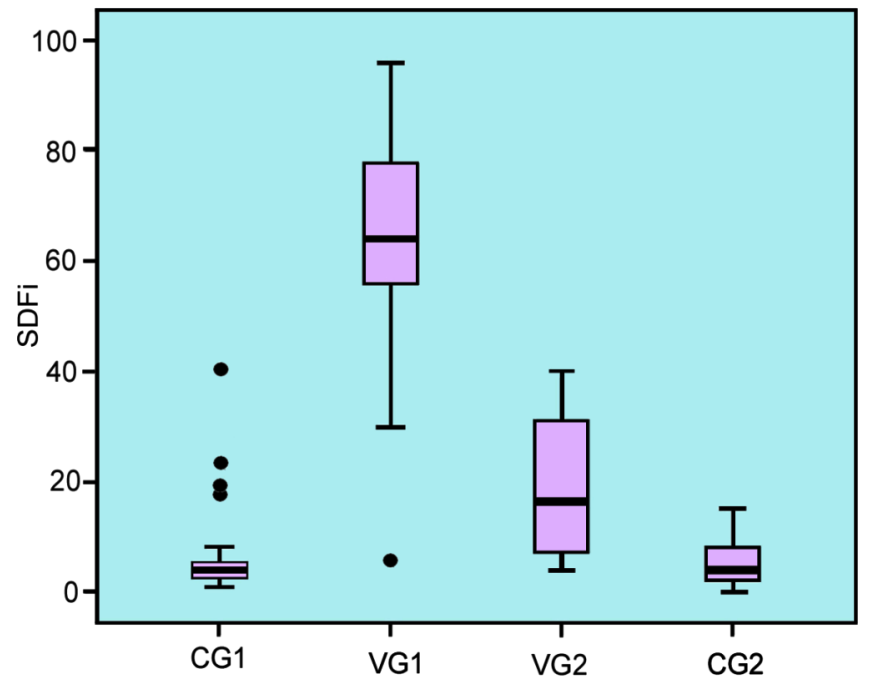

Fig. (2). Descriptive statistics (box-and-whisker plots) of sperm DNA fragmentation index in the four established groups (CG: Control Group; VG: Vaccinated group). See text for details.

Forty days post vaccination (VG2) the SDFi decreased with respect to the VG1 score (one-way ANOVA: $F=37.6$; $\mathrm{p}<0.0001$ for 1 and $41 \mathrm{df}$ ), but was still significantly increased, with a 3.6 fold increase in mean compared to the two outside controls (one-way ANOVA: $F=36.8 ; \mathrm{p}<0.0001$ for 1 and $78 \mathrm{df}$ ). The mean SDFi value $(21.7+10.6)$ for VG2 was also still very high compared with the standard values.

Two main conclusions may be obtained from this work 1) vaccination can temporarily increase sperm DNA fragmentation in ram and 2) sperm DNA fragmentation levels can be restored to normal levels after being elevated following an acute stress event, such as vaccination. Practically, the sudden large increase in the percentage of sperm cells with fragmented DNA after vaccination is another reason to avoid using sperm samples retrieved from animals for artificial reproduction until at least, one month or forty days following vaccination.

It is known that germ line cells are significantly affected by infectious agents as well as by vaccination episodes against those same agents [10]. In boar [17] and in ram [18], the percentage of forward movement and normal spermatozoal morphology and motility were significantly reduced in vaccinated animals. In the male germ line, only spermiogenesis is affected. Meiosis is also likely to be affected by the collateral effects of vaccination, as suggested by the increased occurrence of univalents involving autosomes, as well as sex chromosomes, in a group of mice which were antirabic vaccinated, in comparison with control stocks [19]. In this situation, vaccines could be considered as clastogenic effectors. In the case analyzed here, the time of recovery to a normal rate of sperm DNA fragmentation seems to be related to duration of spemiogenesis, more than to possible mutations or alterations occurring during meiosis. Duration of spermiogenesis varies in different species but is quite constant within each species. Thus, in ram the spermiogenesis encompasses around 18 days, while in bull and stallion it is about 21 days $[20,21]$. The timing here for sperm to reach the maximum levels of sperm DNA fragmentation, coupled with the quick recovery of sperm quality, seems to indicate that spermiogenesis rather than spermatogenesis was af- fected by vaccination. If meiotic cells or gonial cells were affected the time to recover normal cells would be longer than observed here. In the case analysed here from 20 to 30 days was the delay before SDF started to decrease. This suggests that histone/protamine replacement and assembly during sperm maturation were affected. Interestingly, when the effect of foot-and-mouth disease vaccination on the various seminal attributes of buffalo bulls was studied, it was observed that vaccination also produces adverse effects on the standard seminal parameters, up to one month after vaccination [13]. This duration for semen quality recovery is quite similar to that reported here.

The effect of vaccinations on semen parameters is not fully understood. Probably the type of vaccine and genetic background of the animal is determinant of the immune reaction of the individual. Inoculation of live Brucella ovis into the epididymus of rams generated intense epididymal lesions. In addition, an increased numbers of neutrophils, macrophages and lymphocytes were detected, being indicative of induced inflammatory response. Unfortunately, such effects on spermatozoa were not determined in this experiment [22]. However, it is known that leucocytospermia produces oxidative stress that may result in DNA damage [23, 24]. Additionally, vaccination may trigger elevated temperature, either locally through the inflammation process, or generally, inducing fever in some cases. In fact, concentration, motility and morphology may be adversely affected by fever, especially during the period of spermiogenesis [25]. Also sperm chromatin structure seems to be affected by an increase of temperature, causing extensive DNA strand breaks, altering protein synthesis [26] and decreasing the protamine disulfide bonding [27]. Interestingly, in bulls, scrotal mildthermal stress caused sperm morphological abnormalities after 11 days after insulation [28]. They increased during the following days, decreasing near 40 days after scrotal insulation.

The effects of vaccination on sperm quality and particularly on sperm DNA integrity probably consists of many factors and effectors, such as the genetic background, and the capacity to respond to oxidative stress or temperature variations, that finally determines a response for each individual. Substantial interactions between these factors could be an explanation for the high levels of variance in response for sperm DNA fragmentation values observed for animals postvaccination.

\section{ACKNOWLEDGEMENTS}

The authors want to thank Francisca Arroyo for a marvellous technical assistance. This work has been supported by grants from the MEC Petri 480PTR1995-0907-OP, BFU 2007-66340/BFI and CGL2005-02898/BOS.

\section{REFERENCES}

[1] Agarwal A, Allamaneni SS. The effect of sperm DNA damage on assisted reproduction outcomes. A review. Minerva Ginecol 2004; 56(4): 235-245.

[2] Rybar R, Faldikova L, Faldyna M, et al. Bull and boar sperm DNA integrity evaluated by sperm chromatin structure assay in the Czech Republic. Vet Med 2004: 49(1): 1-8.

[3] Waterhouse KE, Haugan T, Kommisrud E, et al. Sperm DNA damage is related to field fertility of semen from young Norwegian Red bulls. Reprod Fertil Dev 2006; 18(7): 781-788. 
[4] Payne JF, Raburn DJ, Couchman GM, et al. Redefining the relationship between sperm deoxyribonucleic acid fragmentation as measured by the sperm chromatin structure assay and outcomes of assisted reproductive techniques. Fertil Steril 2005; 84 (2): 356364.

[5] Belcheva A, Ivanova-Kicheva M, Tzvetkova P, et al. Effects of cigarette smoking on sperm plasma membrane integrity and DNA fragmentation. Int J Androl 2004; 27(5): 296-300.

[6] Rodriguez S, Goyanes V, Segrelles E, et al. Critically short telomeres are associated with sperm DNA fragmentation. Fertil Steril 2005; 84(1): 843-845.

[7] Giwercman A, Richthoff J, Høllund H, et al. Correlation between sperm motility and sperm chromatin structure assay parameters. Fertil Steril 2003; 80(6): 1404-1412.

[8] Borini A, Tarozzi N, Bizzaro D, et al. Sperm DNA fragmentation: paternal effect on early post-implantation embryo development in ART. Hum Reprod 2006; 21(11): 2876-2881.

[9] Givens MD, Waldrop JG. Bovine viral diarrhea virus in embryo and semen production systems. Vet Clin North Am Food Anim Pract 2004; 20(1): 21-38.

[10] Givens MD. A clinical, evidence-based approach to infectious causes of infertility in beef cattle. Theriogenology 2006; 66(3): 648-654.

[11] Bohring C, Krause W. Immune infertility: towards a better understanding of sperm (auto)-immunity. The value of proteomic analysis. Hum Reprod 2003; 18(5): 915-924.

[12] Bandivdekar AH, Vernekar VJ, Kamada M, et al. Antifertility effect of passive administration of antibodies to 80k Da human sperm antigen and its synthetic peptides in male and female rats. Am J Reprod Immunol 2005; 54(6): 332-341.

[13] Singh R, Verma HK, Kumar S. Effect of the foot-and-mouth disease vaccination on the semen quality of buffalo bulls. Indian $\mathrm{J}$ Anim Sci 2003 ; 73(12):1319-1323.

[14] Enciso M, López-Fernández C, Fernández JL, et al. A new method to analyze boar sperm DNA fragmentation under bright-field or fluorescence microscopy. Theriogenology 2006; 65(2): 308-316.

[15] De Ambrogi M, Spinaci M, Galeati G, et al. Viability and DNA fragmentation in differently sorted boar spermatozoa. Theriogenology 2006; 66(8): 1994-2000.
[16] Gosálvez J, Fernández JL, Goyanes V. Análisis de la fragmentación del $\mathrm{ADN}$ en espermatozoides mediante el test de dispersión de la cromatina (SCD). Biotech 2006; 1(1): 38-51.

[17] Christopher-Hennings J, Nelson EA, Nelson JK, et al. Effects of a modified-live virus vaccine against porcine reproductive and respiratory syndrome in boars. Am J Vet Res 1997; 58(1): 40-45.

[8] Kaltenboeck B, Hehnen HR, Vaglenov A. Bovine Chlamydophila spp infection: do we underestimate the impact on fertility? Vet Res Commun 2005; 1(1): 1-15.

[19] Das RK, Nayak R. Spermatocyte chromosome alterations in mice inoculated with antirabies vaccine and tetanus toxoid separately and in combination. Mutat Res 1988; 204(2): 277-282.

[20] Courot M, Hochereau-de Reviers MT, Ortavant R. Spermatogenesis In: Johnson A D, Gomes WR, Vandemark N L (eds ), The Testis, Vol 1 New York: Academic Press 1970; 339-432.

[21] Russell LD, Ettlin RA, Sinha Hikim AP, Clegg ED. Histological and Histopathological Evaluation of the Testis Clearwater, FL: Cache River Press 1990; 41-58.

[22] Rahaley RS, Dennis SM. Histopathology of experimental brucellosis in rams following vaccination with Brucella ovis. Aust Vet $\mathrm{J}$ 1984; 61(11):353-356.

[23] Aitken R J, Krausz C. Oxidative stress, DNA damage and the Y chromosome. Reprod 2001; 22(4): 497-506.

[24] Lemkecher T, Dartigues S, Vaysse J, et al. Leucocytospermia, oxidative stress and male fertility: facts and hypotheses. Gynecol Obstet Fertil 2005; 33(1-2): 2-10.

[25] Carlsen E, Andersson AM, Petersen JH, et al. History of febrile illness and variation in semen quality. Hum Reprod 2003;18(10): 2089-2092.

[26] Evenson DP, Jost LK, Corzett M, et al. Characteristics of human sperm chromatin structure following an episode of influenza and high fever: a case study. J Androl 2000; 21(5): 739-746.

[27] Love CC, Kenney RM. Scrotal heat stress induces altered sperm chromatin structure associated with a decrease in protamine disulfide bonding in the stallion. Biol Reprod 1999; 60: 615-620.

[28] Vogler CJ, Saacke RG, Bame JH, et al. Effects of scrotal insulation on viability characteristics of cryopreserved bovine semen. Journal of Dairy Science 1991; 74(11): 3827-3835. 